\title{
Individual and contextual covariates of burnout: a cross-sectional nationwide study of French teachers Marie-Noël Vercambre*1, Pauline Brosselin ${ }^{1}$, Fabien Gilbert ${ }^{1}$, Eléna Nerrière ${ }^{1}$ and Viviane Kovess-Masféty²
}

Address: ${ }^{1}$ Foundation for Public Health, MGEN, Paris, France and ${ }^{2} E A 4069$, Université Paris Descartes, Paris, France

Email: Marie-Noël Vercambre* - mvercambre@mgen.fr; Pauline Brosselin - muscadeb@tele2.fr; Fabien Gilbert - fgilbert@mgen.fr; Eléna Nerrière - catelinois@free.fr; Viviane Kovess-Masféty - viviane.kovess-masfety@ext.parisdescartes.fr

* Corresponding author

Published: 10 September 2009

BMC Public Health 2009, 9:333 doi: I0.I I86/I47|-2458-9-333
Received: 10 September 2008

Accepted: 10 September 2009

This article is available from: http://www.biomedcentral.com/I47I-2458/9/333

(C) 2009 Vercambre et al; licensee BioMed Central Ltd.

This is an Open Access article distributed under the terms of the Creative Commons Attribution License (http://creativecommons.org/licenses/by/2.0), which permits unrestricted use, distribution, and reproduction in any medium, provided the original work is properly cited.

\begin{abstract}
Background: Limited information on the covariates of burnout syndrome in French teachers is available. The aim of this study was to evaluate the relative contributions of individual and contextual factors on the three burnout dimensions: emotional exhaustion, depersonalization, and reduced personal accomplishment.
\end{abstract}

Methods: The source data come from an epidemiological postal survey on physical and mental health conducted in 2005 among 20,099 education workers (in activity or retired) selected at random from the health plan records of the national education system. The response rate was $52.4 \%$. Teachers in activity currently giving classes to students who participated in the survey $(n=$ 3,940 ) were invited to complete a self-administered questionnaire including the Maslach Burnout Inventory. 2,558 teachers provided complete data (64.9\%). Variables associated with high emotional exhaustion (highest quartile of score), high depersonalization (highest quartile), and reduced personal accomplishment (lowest quartile) were evaluated using multivariate logistic regression. Studied variables referred to demographic characteristics, socio-professional environment, job dissatisfaction, experienced difficulties at work, and teaching motivations.

Results: Different variables were associated with each burnout dimension. Female teachers were more susceptible to high emotional exhaustion and reduced personal accomplishment, whereas male teachers were more susceptible to high depersonalization. Elementary school teachers were more susceptible to high emotional exhaustion, but less susceptible to high depersonalization and reduced personal accomplishment than their higher school level counterparts. Experienced difficulties with pupils were associated with all three dimensions. A socio-economically underprivileged school neighbourhood was also related to high emotional exhaustion and high depersonalization.

Conclusion: Programs to enhance teaching environment might be an interesting approach to try to prevent burnout. It would be useful to take the different dimensions into account in planning the intervention. 


\section{Background}

"Burnout" is a syndrome of emotional exhaustion, depersonalization, and reduced personal accomplishment which arises in response to chronic stress in jobs where individuals work with people [1]. Emotional exhaustion refers to feelings of being emotionally overextended and drained by others. Depersonalization refers to development of dehumanized and cynical attitudes toward people who are recipients of one's services. Reduced personal accomplishment refers to a decline in one's feeling of competence and successful achievement in work. Despite increasing interest in burnout in a wide range of occupations $[2,3]$, the burnout phenomenon has been studied principally in human service professions [4]. In educational settings, interest is growing because the teaching profession has dramatically evolved over recent years, with teaching now demanding more time and energy, but with fewer resources available and a lack of social recognition [5]. In this context, variables associated with burnout in teachers have been studied extensively [6].

Certain background variables have been put forward as potential risk factors for burnout, including gender, age, marital status and grade level taught. Male teachers have been shown to be more susceptible to depersonalization than females $[7,8]$, whereas investigations of the influence of age have yielded more inconsistent findings. On the whole, age seems to be inversely correlated with emotional exhaustion $[9,10]$. With respect to grade level taught, intermediate and high school teachers were more likely to exhibit a higher degree of depersonalization than their elementary school counterparts $[8,9]$.

In addition to background factors, several organizational and personality factors have been related to burnout. Concerning organizational factors, recent investigations have indicated that role conflict, role ambiguity, imbalance of effort and reward, as well as perceptions of job stressors, were important factors in teacher burnout. In particular, the number of pupils [10], time constraints [11], and work overload [12] have been related to a high degree of emotional exhaustion. Erosion of the classroom climate also appears to have an impact on stress and subsequent burnout. Notably, pupil disrespect was associated with a higher degree of emotional exhaustion and depersonalization, whereas pupil lack of sociability was associated with a higher degree of depersonalization and a lower degree of personal accomplishment [13]. Moreover, lack of support (as evaluated through a general measure of social support, including items on emotional support from colleagues and staff members) has been associated with a higher degree of emotional exhaustion and depersonalization [14]. On the whole, job dissatisfaction was closely related to feelings of burnout [15] on all three dimensions. Lastly, individual resources and personality factors have been studied in teacher samples to explain why individuals in the same work environment and having the same educational and experience backgrounds often respond differently in terms of burnout. Notably, neuroticism (which corresponds broadly to individual susceptibility to psychological distress and inability to cope with stress) has been related to higher emotional exhaustion $[4,11,16]$. Other studies have related sense of efficacy [17-19], perception of superiority [20], and hardiness [21] to burnout syndrome.

Overall, the literature indicates that individual characteristics and contextual factors are closely interwoven in the development of burnout in teacher. Nonetheless, findings have been somewhat inconsistent between studies, possibly due, at least in part, to a failure to take into account potential confounding factors adequately in the statistical analysis.

The goal of the present study was to evaluate potential independent associations between a variety of personal and contextual factors and burnout using multivariate techniques. We also wished to test the hypothesis that the association patterns differ for each of the three burnout dimensions, and thereby evaluate the multidimensionality of the burnout syndrome [22]. The choice of individual and contextual variables to evaluate as potential covariates of burnout was inspired by the above literature. To be considered, these should have been sufficiently well documented in the questionnaire used. We also considered some factors that had, to our knowledge, never been studied in relation to burnout, namely the school neighbourhood and the reasons why the teaching profession was chosen. School neighbourhood is a proxy that evaluates neighbourhood-level psychosocial stressors such as experience of incivility, drug misuse, youngsters frequently hanging around, rubbish on the streets, feeling unsafe or dissatisfaction with the quality of green space. In the general population, these stressors have been related to level of perceived stress [23], as well as self-reported health [24]. Our hypothesis was that teachers in socioeconomically underprivileged school neighbourhood will be more exposed to stressful situations and consequently, more susceptible to burnout. Regarding teaching motivations, idealism in teachers could be both a protective factor and a risk factor with respect to certain psychological symptoms. Indeed, idealist teachers are probably more psychologically involved at school, because of their concern toward pupil success. Their mental wellness will then depend on their perceptions that reality and ideals go together well or not [25]. We hypothesized that teachers who declared to have chosen teaching because they felt a calling for that (such as a "desire to make young people grow up") were less susceptible to depersonalization but more susceptible to emotional exhaustion than those 
teachers who declared to have chosen teaching for job security.

In order to test these various hypotheses, we analyzed recent data from a large sample of policyholders of the "Mutuelle Générale de l'Éducation Nationale" (MGEN). This health care insurance company covers everyone currently working or who has previously worked within the public education system in France.

\section{Methods}

\section{Study population and selection process}

The population of the source epidemiological survey was a sample of 20,099 insurance policyholders, aged 18 years or over, selected at random (one in every hundred) from a register of unique policy numbers assigned to individual affiliated members of the MGEN. Of the 20,099 selected policyholders, 49 could not be contacted because they had died, and 411 because their address was incorrect. In January 2005, the 19,639 remaining individuals received a questionnaire by mail, accompanied by a letter explaining that the survey participation was voluntary and that anonymity was ensured through the use of identifying numbers. As required by the observational research regulation in France, this study was approved by both the national authorities responsible for protecting privacy and personal data: the "Comité Consultatif sur le Traitement de l'Information en matière de Recherche dans le domaine de la Santé" (CCTIRS) and the "Commission Nationale de l'Informatique et des Libertés" (CNIL). The global response rate after two consecutive mail shots was $52.4 \%$ (i.e. 10,288 respondents).

The present study was conducted among teachers in active employment who were currently giving classes to students. These were precisely invited to complete a specific part including a questionnaire on burnout. Of the 10,288 respondents, 6,532 were teachers, of whom 3,940 individuals were currently teaching. A further 1,382 individuals were excluded due to missing data for the burnout questionnaire $(n=756)$ or for the covariates of interest $(n=$ 626). The final study sample thus included 2,558 working teachers $(64.9 \%)$ with complete data for all variables studied.

\section{Characteristics of the study sample}

Our study sample reflected the proportion of men and women in the national population of teachers within the public education system (64.7\% women vs. $63.8 \%$ in the French public system [26]) but differed slightly with respect to age and grade level taught. Teachers aged less than 30 were under-represented ( $8 \%$ vs. 16\%) and those aged 50 or more were over-represented (37\% vs. $29 \%$ ). There were also fewer university teachers than expected (7.1\% vs. $9.3 \%)$. In our sample, gender was closely asso- ciated with other variables of interest (Table 1), in particular, with grade level taught, with nursery and primary teachers being predominately female, and secondary school and university teachers predominantly male.

\section{Measurement of burnout}

The French version of the Maslach Burnout Inventory [1] adapted to education settings (MBI-ES [27]) was used to evaluate burnout syndrome among teachers participating in the study.

The MBI is nowadays the most widely used instrument to measure burnout in individuals [2]. The 22-item version of the MBI consists of nine items that measure emotional exhaustion, five items that measure depersonalization, and eight items that measure personal accomplishment. Each item can be answered on a 7-point Likert scale ranging from "never" $(=0)$ to "daily" $(=6)$. High scores on emotional exhaustion and depersonalization and low scores on personal accomplishment are indicative of burnout.

The general version of the MBI was validated in French in two samples of day-care workers and nurses in Quebec [28]. The reliability and validity of the instrument has also been confirmed in a sample of French teachers [29]. In the current study, Cronbach's alpha coefficients were 0.87 for the emotional exhaustion subscale, 0.61 for depersonalization, and 0.82 for personal accomplishment.

\section{Outcomes of interest}

Maslach and Jackson originally considered burnout subscale scores as continuous variables which could be expressed as a degree of severity ranging from low to medium to high [1]. They did not define a clinical threshold that indicated the presence or absence of burnout. In contrast, others have conceptualized these scores as dichotomous, in order to distinguish individuals with serious burnout symptoms from others. To this end, cutoff scores corresponding to burnout diagnosis (when available) [14], or to the extreme quartile of MBI scores have been proposed [30]. For the purposes of this study, we adapted this latter approach. Emotional exhaustion and depersonalization were respectively assigned a value of '1' (presence of burnout symptom) when scores were above the $3^{\text {rd }}$ quartile, whereas personal accomplishment was assigned a value of ' 1 ' if the score was below the $1^{\text {st }}$ quartile. A major advantage of this dichotomous approach based on the extreme quartile is that it eliminates the problem of potentially small sample sizes for case groups and permits subsequent use of logistic regression models to test associations between burnout and variables of interest. Such models are well adapted to this purpose, since no a priori hypotheses are needed concern- 
Table I: Description of the study sample by gender

\begin{tabular}{|c|c|c|c|c|}
\hline & $\begin{array}{c}\text { Men } \\
\mathbf{n}=\mathbf{9 0 2} \\
\%\end{array}$ & $\begin{array}{c}\text { Women } \\
n=1,656 \\
\%\end{array}$ & $\begin{array}{c}\text { Total } \\
\mathrm{n}=\mathbf{2 , 5 5 8} \\
\%\end{array}$ & $\mathbf{p}$ \\
\hline Gender & 35.3 & 64.7 & 100 & \\
\hline Age & & & & $<0.01$ \\
\hline$<30$ years & 8.8 & 7.2 & 7.7 & \\
\hline 30 to 39 years & 24.7 & 30.9 & 28.7 & \\
\hline 40 to 49 years & 25.4 & 28.0 & 27.1 & \\
\hline$\geq 50$ years & 41.1 & 33.9 & 36.5 & \\
\hline Marital status & & & & $<0.01$ \\
\hline Single & 22.7 & 24.5 & 23.9 & \\
\hline In couple & 69.3 & 60.6 & 63.6 & \\
\hline Previously married & 8.0 & 14.9 & 12.5 & \\
\hline Grade level taught & & & & $<0.01$ \\
\hline Nursery school & 2.8 & 19.0 & 13.3 & \\
\hline Primary school & 18.9 & 27.1 & 24.2 & \\
\hline Early secondary school & 25.6 & 25.7 & 25.7 & \\
\hline Secondary school & 23.7 & 14.7 & 17.9 & \\
\hline Vocational school & 12.5 & 6.8 & 8.8 & \\
\hline University & 12.1 & 4.4 & 7.1 & \\
\hline Special classes for pupils with learning disabilities & 4.4 & 2.4 & 3.1 & \\
\hline Teaching social neighbourhood $\dagger$ & & & & 0.45 \\
\hline Normal & 81.4 & 80.1 & 80.6 & \\
\hline Underprivileged & 18.6 & 19.9 & 19.4 & \\
\hline
\end{tabular}

* Chi ${ }^{2}$ test

† As defined by the French Ministry of Education

ing 'normality' and homogeneity of variance, and because non linear phenomena can be detected.

Each dichotomous outcome (MBI subscale score assignment) was modelled independently, in order to preserve the multidimensional evaluation of burnout. Indeed, these three conceptually distinct burnout dimensions have been confirmed empirically in populations of teachers through both factor analysis and internal consistency studies [31-33].

\section{Description of study variables}

We regrouped the potential covariates of burnout studied into three categories, corresponding to demographic characteristics, socio-professional environment and other work-related factors.

The first category comprised gender, age and marital status. Age was divided into four groups: < 30 years; 30-39 years; 40-49 years; $\geq 50$ years; marital status was divided into three groups: single; in couple; previously married (widowed, divorced, or separated).

The socio-professional environment was described through the grade level, the teaching social neighbour- hood, and the number of pupils. Grade level was divided into seven categories: nursery school; primary school; early secondary school; secondary school; university; vocational school; special classes for pupils with learning disabilities. Social school neighbourhood was appraised through a dichotomous variable indicating if or not the school was localized in an "educational priority area", a definition of socioeconomically underprivileged areas introduced by the French Ministry of Education in 1981. This notion was used to guide education policies aimed at correcting social, economic and cultural inequality by concentrating educational investment in areas where student failure was highest. Concerning the number of pupils, a three-category variable (low, in the norm, high) was constructed depending on the median class size observed in the corresponding grade level: number of pupils less than (the median - 2); comprised in the median \pm 2 range; greater than (the median +2 ).

Other work-related variables dealt with reported dissatisfaction with certain job aspects (timetable, time constraints, salary, resources, training), experienced difficulties with others (pupils, colleagues, parents, administration), as well as reasons for choosing the teaching profession (job security, feeling a calling for teaching). 
Each of these variables was investigated in the self administered questionnaire in a yes/no mode and coded dichotomously.

\section{Statistical analysis}

In a first step, we described the distribution of the scores obtained in the study sample for each of the three burnout subscales and compared mean scores obtained with other similar studies of teachers performed elsewhere in Europe.

In a second step, for each of the three burnout dimensions, we compared frequency distributions of the variables of interest between subjects assigned to the burnout group (according to extreme score quartile) and the nonburnout reference group.

Finally, we related the probability of being in the burnout group with the variables of interest using logistic regression models, initially considering each variable separately to evaluate the unadjusted association with the burnout dimension (bivariate analysis) and subsequently introducing all variables into a multivariate model in order to evaluate potentially independent associations when adjusting for confounders. The strength of the associations identified are presented as odds ratios together with their 95 percent confidence intervals (OR [95\%CI]).

All analyses were performed using Stata SE 9 software. A probability threshold of 0.05 was considered statistically significant and all statistical tests were two sided.

\section{Results}

\section{Descriptive analysis of burnout dimension scores}

Table 2 presents the scores observed in the study sample for the three dimensions of burnout. Mean scores (standard deviations) were 18.1 (10.2) for emotional exhaustion, 3.3 (3.7) for depersonalization, and 31.2 (8.6) for personal accomplishment. Table 3 presents comparable values in Europe that were picked up from the literature [13-15,29,34-41].

\section{Bivariate analysis}

In the unadjusted analysis step (Table 4), each of the burnout dimensions was associated with a specific set of covariates. The sets of variables associated with emotional exhaustion and with depersonalization were quite similar, although for two variables, gender and grade level taught, the associations were in the opposite directions for these two dimensions. In contrast, the set of variables associated with reduced personal accomplishment contained a smaller number of quite different variables.

\section{Multivariate analysis}

In the fully-adjusted logistic regression model (Table 5), a high score on the emotional exhaustion subscale was significantly associated with female gender, age $\geq 50$ years, teaching in a nursery or a primary school, teaching in an underprivileged neighbourhood, teaching big classes, as well as reporting dissatisfaction with time constraints, timetable, salary and resources; having chosen the teaching profession for job security; and complaining of difficulties with pupils, colleagues or administration.

A high score on the depersonalization subscale was significantly associated with male gender, being single, teaching in an early secondary or a secondary school, teaching in an underprivileged neighbourhood, as well as reporting dissatisfaction with training; having chosen the teaching profession for job security; and complaining of difficulties with pupils and with administration.

A low score on the personal accomplishment subscale was significantly associated with female gender, being single, teaching in higher grade level (early secondary school, secondary school, vocational school and university), as well as reporting dissatisfaction with training and complaining of difficulties with pupils or with parents. Those who declared having chosen the teaching profession because they felt a calling for that were less susceptible to reduced personal accomplishment than those who did not. Particularly pronounced were the effects associated with the highest grade level taught, as compared with primary school.

\section{Discussion}

This study on the personal and contextual factors associated with burnout in French teachers confirms a number of facts about burnout in this profession and also provides additional information about this syndrome. Our main finding relates to the multi-dimensionality of the burnout syndrome. Indeed, each of the three burnout dimension was associated with a specific set of covariates, and the effect of a given variable could possibly be in the opposite direction for different dimensions, as was the case for gen-

Table 2: Scores on the three burnout dimensions in the study sample

\begin{tabular}{lcccccccccccc}
\hline & \multicolumn{4}{c}{ Emotional Exhaustion } & \multicolumn{4}{c}{ Depersonalization } & \multicolumn{3}{c}{ Personal Accomplishment } \\
\hline $\mathrm{n}$ & mean (sd) & $\mathrm{ql}$ & median & $\mathrm{q} 3$ & mean (sd) & ql & median & $\mathrm{q} 3$ & mean (sd) & $\mathrm{ql}$ & mean & $\mathrm{q} 3$ \\
2,558 & $18.1(\mathrm{I} 0.2)$ & 10 & 17 & 24 & $3.3(3.7)$ & 1 & 2 & 5 & $31.2(8.6)$ & 26 & 32 & 38 \\
\hline
\end{tabular}

sd: standard deviation; q I: first quartile; q3: third quartile 
Table 3: Scores on the three burnout dimensions: comparison with other studies of teachers in Europe

\begin{tabular}{|c|c|c|c|c|c|c|}
\hline $\mathbf{N}$ & Population & Localization & Reference & $\begin{array}{c}\text { Emotional exhaustion } \\
\text { mean (sd) }\end{array}$ & $\begin{array}{l}\text { Depersonalization } \\
\text { mean (sd) }\end{array}$ & $\begin{array}{c}\text { Personal } \\
\text { accomplishment } \\
\text { mean (sd) }\end{array}$ \\
\hline 2,258 & Teachers & France & Present study & I8.1 (10.2) & $3.3(3.7)$ & $31.2(8.6)$ \\
\hline 100 & Primary school teachers & United Kingdom & {$[13]$} & $23.4(10.3)$ & $4.6(4.3)$ & $37.2(6.4)$ \\
\hline 365 & Mathematics teachers & Netherlands & {$[14]$} & $14.0(8.1)$ & $5.6(3.5)$ & $27.3(6.4)$ \\
\hline 100 & $\begin{array}{l}\text { Primary and secondary } \\
\text { school teachers }\end{array}$ & Greece & {$[15]$} & $15.0(8.4)$ & $3.9(3.4)$ & $39.7(5.4)$ \\
\hline 217 & Teachers & France & [29] & $15.0 *$ & $4.5^{*}$ & $30.6 *$ \\
\hline 299 & $\begin{array}{l}\text { Representative sample of } \\
\text { teachers }\end{array}$ & Italy & [29] & $18.5^{*}$ & $3.1^{*}$ & $33.9 *$ \\
\hline 304 & $\begin{array}{l}\text { Secondary school } \\
\text { teachers }\end{array}$ & Netherlands & {$[34]$} & $18.2(1.2)$ & $5.6(5.4)$ & $34.7(7.4)$ \\
\hline 215 & id & Greece & {$[35]$} & $14.5(10.3)$ & $2.9(3.7)$ & $37.4(8.0)$ \\
\hline 169 & id & Italy & [36] & $20.0(13.1)$ & $2.3(3.7)$ & $35.8(8.1)$ \\
\hline 198 & id & Spain & [37] & $21.2(11.1)$ & $3.6(4.1)$ & $31.9(9.2)$ \\
\hline 297 & id & Germany & [38] & $18.5(9.6)$ & $4.2(4.4)$ & $32.5(8.0)$ \\
\hline 232 & id & Finland & [39] & $19.5(10.6)$ & $3.6(3.9)$ & $32.8(8.0)$ \\
\hline 166 & id & United Kingdom & [40] & 28.5 (11.9) & $8.6(6.6)$ & $29.0(8.5)$ \\
\hline 128 & id & Belgium & {$[4 I]$} & $20.4(13.3)$ & $4.2(4.1)$ & $31.3(9.2)$ \\
\hline
\end{tabular}

*Standard deviation not available sd: standard deviation

der and grade level. This multi-dimensionality has been previously highlighted in teachers [11] as well as in diverse other professional groups [42], and should not be ignored when designing studies of burnout or intervention in that field.

Compared to various other studies of burnout in teachers in Europe, the mean dimension scores were essentially similar. However, it should be borne in mind that the study samples were not always comparable across studies. For instance, some included only secondary school teachers, one sample only primary teachers, one another only mathematics teachers. Given the importance of the population structure on the risk of burnout (with respect to gender and grade level repartition in particular), these figures have to be compared with caution. Our findings on burnout covariates cast new light on risk factors for burnout in teachers, complementing results obtained previously in other European studies [43].

In this study, gender was shown to be an important covariate of burnout, although the effect was not on the same direction for all dimensions. After adjustment for potential confounders (in particular, grade level), men were more susceptible to depersonalization, whereas women were more susceptible to emotional exhaustion and to reduced personal accomplishment. Gender differences in sources of stress and in social support may explain, in part, these observations [7]. Even when women hold outside employment (as was the case for female teachers in our sample), they still continue to take main responsibility for housework and children [44]. The combined demands of home and work life may result in higher level of psychological strain, whose long-term consequence could be a loss of energy (e.g. symptoms of emotional exhaustion) together with a withdrawal from work (and then a lower level of personal accomplishment). An element that may also contribute to gender differences in burnout symptoms is internalization of societal expectations. In particular, accepted norms associated with the male gender role emphasize strength, independence, professional achievement and invulnerability [45]. These may make men more likely to cope with their stress by developing dehumanized attitudes. In contrast, accepted norms associated with the female gender role emphasize softness and relationship. To cope with their stress without breaking these norms, women would be more susceptible to emotional exhaustion than depersonalization. On the whole, gender specificities in burnout were consistent with the sex differences in neuropsychiatric disease vulnerability, with women being at least twice as likely as men to suffer from depression and anxiety disorders [46].

Grade level was also shown in our study to be an essential associate of burnout. The representation of all grade levels in our dataset allowed us to evaluate the influence of this variable on the different dimensions of burnout. Emotional exhaustion scores were found to be higher in elementary school teachers than in teachers in early secondary schools, in secondary schools and universities. Conversely, depersonalization was associated with teaching in an early secondary school or, to a lesser extent, in a secondary school. Reduced personal accomplishment was also closely linked with teaching in secondary schools and 
Table 4: Bivariate associations with each of the three burnout dimensions: odds ratios and their $95 \%$ confidence intervals for demographic characteristics, socio-professional environment and work-related factors

\begin{tabular}{|c|c|c|c|c|c|c|c|c|c|c|c|}
\hline \multicolumn{3}{|c|}{ Emotional exhaustion } & \multicolumn{4}{|c|}{ Depersonalization } & \multicolumn{5}{|c|}{ Personal accomplishment } \\
\hline High* & Probability of $h$ & core† & Ref & High* & Probability of $h$ & core & Ref & Low* & Pro & ility of I & core $\dagger$ \\
\hline$\%$ & $95 \% \mathrm{Cl}$ & $\mathbf{p}$ & $\%$ & $\%$ & 95\%Cl & $\mathbf{p}$ & $\%$ & $\%$ & OR & $95 \% \mathrm{Cl}$ & $\mathbf{p}$ \\
\hline
\end{tabular}

\section{Demographic characteristics}

Gender

Men
Women

Age

$<30$ years

30 to 39 years

40 to 49 years

$\geq 50$ years

Marital status

Single

Couple

Previously married

$\begin{array}{ccccccccccccccc}38.1 & 26.6 & 1 & & & 32.6 & 45.6 & 1 & & & 36.0 & 33.1 & 1 & \\ 61.9 & 73.4 & 1.7 & 1.4-2.1 & <0.01 & 67.4 & 54.4 & 0.6 & 0.5-0.7 & <0.01 & 64.0 & 66.9 & 1.1 & 0.9-1.4 & 0.18 \\ & & & & & & & & & & & & & & \\ 7.8 & 7.7 & 1.1 & 0.8-1.6 & 0.56 & 7.5 & 8.7 & 1.3 & 0.9-1.9 & 0.17 & 8.4 & 5.7 & 0.7 & 0.5-1.1 & 0.10 \\ 28.8 & 28.5 & 1.1 & 0.9-1.4 & 0.38 & 28.3 & 30.4 & 1.2 & 0.9-1.6 & 0.16 & 29.0 & 28.0 & 1.0 & 0.8-1.3 & 0.82 \\ 27.8 & 24.6 & 1 & & & 27.7 & 24.6 & 1 & & & 27.5 & 25.8 & 1 & & \\ 35.6 & 39.2 & 1.2 & 1.0-1.6 & 0.06 & 36.5 & 36.4 & 1.1 & 0.9-1.4 & 0.37 & 35.1 & 40.5 & 1.2 & 1.0-1.5 & 0.08 \\ & & & & & & & & & & & & & & \\ 23.3 & 25.6 & 1.2 & 1.0-1.5 & 0.12 & 22.9 & 27.6 & 1.3 & 1.0-1.6 & 0.02 & 22.9 & 26.9 & 1.3 & 1.0-1.5 & 0.04 \\ 64.8 & 60.0 & 1 & & & 64.7 & 59.6 & 1 & & & 64.6 & 60.8 & 1 & & \\ 11.9 & 14.4 & 1.3 & 1.0-1.7 & 0.05 & 12.4 & 12.8 & 1.1 & 0.8-1.5 & 0.46 & 12.5 & 12.3 & 1.0 & 0.8-1.4 & 0.78\end{array}$

Socioprofessional environment

Grade level taught

Nursery school

Primary sch

Early secondary school

Secondary school

Vocational school

University

Special classes for pupils with learning disabilities

Teaching social neighbourhood $\ddagger$

$$
\text { Normal }
$$

Underprivileged

Number of pupils taught $\S$

$$
\text { Low }
$$

In the norm

$$
\text { High }
$$

$\begin{array}{ccccccc}12.5 & 15.8 & 0.9 & 0.7-1.2 & 0.60 & 14.4 & 8.9 \\ 22.1 & 30.4 & 1 & & & 25.2 & 19.9 \\ 25.4 & 26.4 & 0.8 & 0.6-1.0 & 0.03 & 23.7 & 33.7 \\ 19.6 & 12.6 & 0.5 & 0.3-0.6 & <0.01 & 17.6 & 18.9 \\ 9.3 & 7.5 & 0.6 & 0.4-0.9 & <0.01 & 9.2 & 7.5 \\ 8.2 & 3.5 & 0.3 & 0.2-0.5 & <0.01 & 7.1 & 6.8 \\ 2.9 & 3.7 & 0.9 & 0.5-1.5 & 0.78 & 2.8 & 4.3\end{array}$

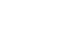

17.6 $\begin{array}{lll}82.4 & 74.9 & \text { I }\end{array}$

$\begin{array}{ccc}27.3 & 21.1 & 0.7 \\ 52.5 & 55.5 & \mathrm{I}\end{array}$

$\begin{array}{ccc}52.5 & 55.5 & 1 \\ 20.3 & 23.4 & 1.1\end{array}$

Work-related factors

Satisfied with time constraints Unsatisfied

Satisfied with time table

Unsatisfied

Satisfied with salary

Unsatisfied

Satisfied with resources

Unsatisfied

$\begin{array}{ccc}93.3 & 84.6 & \text { I } \\ 6.7 & 15.4 & 2.5 \\ 88.6 & 79.8 & \text { I } \\ 11.4 & 20.2 & 2.0 \\ 52.2 & 35.5 & \text { I } \\ 47.8 & 64.5 & 2.0 \\ 50.6 & 36.3 & \text { I } \\ 49.4 & 63.7 & 1.8\end{array}$

\begin{tabular}{lll}
82.1 & 74.7 \\
\hline & 8.1
\end{tabular}

$\begin{array}{lllll}1.3-1.9 & <0.01 & 17.9 & 25.3 & 1.6\end{array}$

$\begin{array}{lllll}0.6-0.9 & <0.01 & 25.9 & 25.1 & 0.9\end{array}$

$0.9-1.4$

0.46

$\begin{array}{ccc}25.9 & 25.1 & 0.9 \\ 53.0 & 54.2 & 1\end{array}$

$0.5-1.1$
$1.4-2.4$
$1.0-1.9$
$0.7-1.6$
$0.8-1.8$
$1.1-3.3$

0.20
$<0.01$
0.05
0.84
0.40
0.02

$13.9 \quad 11.3$

$26.5 \quad 17.0$

$\begin{array}{lll}26.1 & 24.6 & 1.5\end{array}$

$\begin{array}{lll}15.5 & 25.2 & 2.5\end{array}$

$\begin{array}{lll}8.1 & 11.0 & 2.1\end{array}$

$\begin{array}{lll}6.2 & 9.8 & 2.5\end{array}$

$3.7 \quad$ I.

I.I 0.5

$\begin{array}{llll}79.8 & 82.8 & \text { । }\end{array}$

$\begin{array}{lllll}1.2-1.9 & <0.01 & 20.2 & 17.2 & 0.8\end{array}$

$\begin{array}{lllll}0.8-1.2 & 0.66 & 25.0 & 28.2 & 1.2\end{array}$

$0.7-1.2$

0.7-1.2 $0.74 \quad 21.1 \quad 20.6$

$53.9 \quad 51.2 \quad 1$

1.0

$0.8-1.3$

0.83

$\begin{array}{ccccc} & & 92.2 & 87.2 & \text { I } \\ 1.9-3.3 & <0.01 & 7.8 & 12.8 & 1.7 \\ & & 87.6 & 81.8 & \text { I } \\ 1.5-2.5 & <0.01 & 12.4 & 18.2 & 1.6 \\ & & 49.5 & 42.9 & \text { I } \\ 1.6-2.4 & <0.01 & 50.5 & 57.1 & 1.3 \\ & & 48.7 & 40.8 & \text { I } \\ 1.5-2.2 & <0.01 & 51.3 & 59.2 & 1.4\end{array}$

$0.8-1.5 \quad 0.53$

$0.9-1.5 \quad 0.36$

$0.7-1.1 \quad 0.17$ 
Table 4: Bivariate associations with each of the three burnout dimensions: odds ratios and their $95 \%$ confidence intervals for demographic characteristics, socio-professional environment and work-related factors (Continued)

\begin{tabular}{|c|c|c|c|c|c|c|c|c|c|c|c|c|c|c|c|}
\hline Satisfied with training & 40.8 & 30.6 & 1 & & & 39.3 & 34.0 & 1 & & & 39.0 & 36.2 & 1 & & \\
\hline Unsatisfied & 59.2 & 69.4 & 1.6 & $1.3-1.9$ & $<0.01$ & 60.7 & 66.0 & 1.3 & $1.0-1.5$ & 0.03 & 61.0 & 63.8 & 1.1 & $0.9-1.4$ & 0.22 \\
\hline $\begin{array}{l}\text { Have chosen to be teacher for the job } \\
\text { security }\end{array}$ & 38.8 & 47.5 & 1.4 & $1.2-1.7$ & $<0.01$ & 39.3 & 47.4 & 1.4 & I.I-I.7 & $<0.01$ & 40.6 & 42.0 & 1.1 & $0.9-1.3$ & 0.51 \\
\hline Not for this reason particularly & 61.2 & 52.5 & 1 & & & 60.7 & 52.6 & 1 & & & 59.4 & 58.0 & 1 & & \\
\hline $\begin{array}{l}\text { Have chosen to be teacher because } \\
\text { felt a calling for that }\end{array}$ & 33.1 & 34.6 & 1.1 & $0.9-1.3$ & 0.50 & 34.3 & 30.0 & 0.8 & $0.7-1.0$ & 0.06 & 37.1 & 22.4 & 0.5 & $0.4-0.6$ & $<0.01$ \\
\hline Not for this reason particularly & 66.9 & 65.4 & 1 & & & 65.7 & 70.0 & I & & & 62.9 & 77.6 & I & & \\
\hline No difficulties with pupils & 61.8 & 44.2 & 1 & & & 61.2 & 42.6 & I & & & 60.0 & 49.9 & I & & \\
\hline Difficulties & 38.2 & 55.8 & 2.0 & $1.7-2.5$ & $<0.01$ & 38.8 & 57.4 & 2.1 & $1.8-2.6$ & $<0.01$ & 40.0 & 50.1 & 1.5 & $1.3-1.8$ & $<0.01$ \\
\hline No Difficulties with parents & 84.9 & 72.2 & 1 & & & 82.8 & 77.8 & I & & & 82.9 & 78.4 & 1 & & \\
\hline Difficulties & 15.1 & 27.8 & 2.2 & $1.7-2.7$ & $<0.01$ & 17.2 & 22.2 & 1.4 & $1.1-1.7$ & $<0.01$ & 17.1 & 21.6 & 1.3 & $1.1-1.7$ & 0.01 \\
\hline No difficulties with Colleagues & 88.2 & 79.0 & 1 & & & 86.6 & 83.2 & 1 & & & 86.2 & 85.0 & I & & \\
\hline Difficulties & 11.8 & 21.0 & 2.0 & $1.6-2.5$ & $<0.01$ & 13.4 & 16.8 & 1.3 & $1.0-1.7$ & 0.04 & 13.8 & 15.0 & 1.1 & $0.9-1.4$ & 0.46 \\
\hline No difficulties with the administration & 85.1 & 73.6 & 1 & & & 84.7 & 72.7 & 1 & & & 83.1 & 80.0 & I & & \\
\hline Difficulties & 14.9 & 26.4 & 2.0 & $1.6-2.5$ & $<0.01$ & 15.3 & 27.3 & 2.1 & $1.7-2.6$ & $<0.01$ & 16.9 & 20.0 & 1.2 & $1.0-1.5$ & 0.08 \\
\hline
\end{tabular}

OR: odds ratio; $95 \% \mathrm{Cl}: 95$ percent confidence interval

* 'High score' means 'in the highest quartile of the scores observed in the sample', 'low score' means 'in the lowest quartile'

† Probability modelled through an univariate logistic regression analysis

$¥$ As defined by the French Ministry of Education

$\S$ The number of pupils taught was divided into three groups depending on the median class size observed in the corresponding grade level taught: number of pupils taught less than (the median

-2 ); comprised in the median \pm 2 range; greater than (the median +2 ) 
Table 5: Multivariate associations with each of the three burnout dimensions: odds ratios and their $95 \%$ confidence intervals for demographic characteristics, socio-professional environment and work-related factors

\begin{tabular}{|c|c|c|c|c|c|c|c|c|c|}
\hline & \multicolumn{3}{|c|}{$\begin{array}{c}\text { Emotional exhaustion } \\
\text { High score* }\end{array}$} & \multicolumn{3}{|c|}{$\begin{array}{c}\text { Depersonalization } \\
\text { High score* }\end{array}$} & \multicolumn{3}{|c|}{$\begin{array}{c}\text { Personal accomplishment } \\
\text { Low score*t }\end{array}$} \\
\hline & OR & $95 \% \mathrm{Cl}$ & $\mathbf{p}$ & OR & $95 \% \mathrm{Cl}$ & $\mathbf{p}$ & OR & $95 \% \mathrm{Cl}$ & $\mathbf{p}$ \\
\hline \multicolumn{10}{|l|}{ Demographic characteristics } \\
\hline \multicolumn{10}{|l|}{ Gender } \\
\hline Men & 1 & & & I & & & I & & \\
\hline Women & 1.6 & I.3-2.0 & $<0.01$ & 0.6 & $0.5-0.7$ & $<0.01$ & 1.4 & I.I-I.7 & $<0.01$ \\
\hline \multicolumn{10}{|l|}{ Age } \\
\hline$<30$ years & 1.4 & $0.9-2.1$ & 0.10 & 1.1 & $0.7-1.7$ & 0.54 & 0.7 & $0.5-1.1$ & 0.14 \\
\hline 30 to 39 years & 1.0 & $0.8-1.4$ & 0.73 & 1.0 & $0.8-1.4$ & 0.75 & 1.0 & $0.7-1.2$ & 0.70 \\
\hline 40 to 49 years & 1 & & & 1 & & & 1 & & \\
\hline$\geq 50$ years & 1.7 & I.3-2.I & $<0.01$ & 1.1 & $0.8-1.4$ & 0.62 & 1.2 & $0.9-1.5$ & 0.13 \\
\hline \multicolumn{10}{|l|}{ Marital status } \\
\hline Single & 1.2 & $0.9-1.5$ & 0.17 & 1.3 & $1.0-1.6$ & 0.05 & 1.4 & I.I-I.7 & $<0.01$ \\
\hline Couple & 1 & & & 1 & & & I & & \\
\hline Previously married & 1.1 & $0.8-1.4$ & 0.68 & 1.1 & $0.8-1.6$ & 0.43 & 1.0 & $0.7-1.3$ & 0.89 \\
\hline \multicolumn{10}{|l|}{ Socioprofessional environment } \\
\hline \multicolumn{10}{|l|}{ Grade level taught } \\
\hline Nursery school & 0.8 & $0.6-1.1$ & 0.21 & 0.9 & $0.6-1.3$ & 0.46 & 1.1 & $0.8-1.6$ & 0.46 \\
\hline Primary school & 1 & & & 1 & & & 1 & & \\
\hline Early secondary school & 0.7 & $0.5-0.9$ & $<0.01$ & 1.7 & 1.2-2.2 & $<0.01$ & 1.5 & I.I-2.0 & $<0.01$ \\
\hline Secondary school & 0.6 & $0.4-0.8$ & $<0.01$ & 1.4 & I.0-2.0 & 0.03 & 2.9 & $2.1-4.0$ & $<0.01$ \\
\hline Vocational school & 0.8 & $0.5-1.1$ & 0.17 & 1.1 & $0.7-1.7$ & 0.74 & 2.6 & $1.7-3.8$ & $<0.01$ \\
\hline University & 0.4 & $0.3-0.7$ & $<0.01$ & 1.5 & $0.9-2.4$ & 0.11 & 3.4 & $2.2-5.2$ & $<0.01$ \\
\hline Special classes for pupils with learning disabilities & 0.8 & $0.5-1.4$ & 0.44 & 1.5 & $0.9-2.8$ & 0.14 & 0.6 & $0.2-1.3$ & 0.17 \\
\hline \multicolumn{10}{|l|}{ Teaching social neighbourhood $\ddagger$} \\
\hline Normal & I & & & 1 & & & 1 & & \\
\hline Underprivileged & 1.4 & I.I-I.8 & $<0.01$ & 1.5 & $1.1-1.9$ & $<0.01$ & 1.0 & $0.7-1.2$ & 0.77 \\
\hline \multicolumn{10}{|l|}{ Number of pupils taught $\S$} \\
\hline Low & I & & & I & & & 1 & & \\
\hline In the norm & 0.8 & $0.6-1.0$ & 0.07 & 0.9 & $0.7-1.2$ & 0.48 & 1.1 & $0.9-1.3$ & 0.54 \\
\hline High & 1.3 & $1.0-1.7$ & 0.05 & 1.1 & $0.8-1.4$ & 0.71 & 0.9 & $0.7-1.2$ & 0.40 \\
\hline \multicolumn{10}{|l|}{ Work-related factors } \\
\hline Satisfied with time constraints & I & & & I & & & I & & \\
\hline Unsatisfied & 1.5 & I.I-2.2 & 0.01 & 1.2 & $0.9-1.8$ & 0.25 & 1.1 & $0.8-1.6$ & 0.65 \\
\hline Satisfied with time table & 1 & & & 1 & & & I & & \\
\hline Unsatisfied & 1.5 & $1.1-2.0$ & $<0.01$ & 1.2 & $0.9-1.7$ & 0.17 & 1.0 & $0.8-1.4$ & 0.86 \\
\hline Satisfied with salary & 1 & & & 1 & & & 1 & & \\
\hline Unsatisfied & 1.7 & I.4-2.I & $<0.01$ & $\mathrm{I.I}$ & $0.9-1.4$ & 0.21 & 0.9 & $0.7-1.1$ & 0.23 \\
\hline Satisfied with resources & 1 & & & 1 & & & 1 & & \\
\hline Unsatisfied & 1.4 & I.I-I.7 & $<0.01$ & 1.2 & I.0-I.5 & 0.08 & 1.1 & $0.9-1.3$ & 0.61 \\
\hline Satisfied with training & I & & & I & & & I & & \\
\hline Unsatisfied & 1.2 & $0.9-1.4$ & 0.20 & 1.3 & $1.0-1.6$ & 0.05 & 1.3 & $1.0-1.6$ & 0.02 \\
\hline Have chosen to be teacher for the job security & 1.4 & I.I-I.7 & $<0.01$ & 1.3 & I.I-I.6 & 0.01 & 1.0 & $0.8-1.2$ & 0.87 \\
\hline Not for this reason particularly & 1 & & & 1 & & & 1 & & \\
\hline Have chosen to be teacher because felt a calling for that & 1.0 & $0.8-1.3$ & 0.84 & 0.8 & $0.7-1.0$ & 0.10 & 0.5 & $0.4-0.6$ & $<0.01$ \\
\hline Not for this reason particularly & 1 & & & $\mathrm{I}$ & & & 1 & & \\
\hline No difficulties with pupils & I & & & I & & & I & & \\
\hline Difficulties & 1.7 & $1.3-2.0$ & $<0.01$ & 1.7 & I.4-2.I & $<0.01$ & 1.5 & $1.2-1.9$ & $<0.01$ \\
\hline No Difficulties with parents & 1 & & & 1 & & & 1 & & \\
\hline Difficulties & 1.2 & $0.9-1.6$ & 0.15 & 1.2 & $0.9-1.5$ & 0.28 & 1.5 & $1.1-1.9$ & $<0.01$ \\
\hline No difficulties with Colleagues & 1 & & & 1 & & & 1 & & \\
\hline Difficulties & 1.4 & $1.1-1.9$ & 0.01 & 1.1 & $0.8-1.5$ & 0.61 & 1.0 & $0.8-1.4$ & 0.89 \\
\hline No difficulties with the administration & 1 & & & 1 & & & 1 & & \\
\hline Difficulties & 1.6 & I.3-2.I & $<0.01$ & 1.6 & $1.2-2.0$ & $<0.01$ & 1.0 & $0.8-1.3$ & 0.82 \\
\hline
\end{tabular}

OR: odds ratio; $95 \% \mathrm{Cl}$ : 95 percent confidence interval

* 'High score' means 'in the highest quartile of the scores observed in the sample', 'low score' means 'in the lowest quartile'

† Probability modelled through a full logistic regression analysis including simultaneously all variables listed above

$\ddagger$ As defined by the French Ministry of Education

$\S$ The number of pupils taught was divided into three groups depending on the median class size observed in the corresponding grade level taught: number of pupils taught less than (the median -2 ); comprised in the median \pm 2 range; greater than (the median +2 ) 
in higher education. Difference in the work environment and in the sources of stress between grade levels (notably, pupils' attitudes and relationships with teachers, which evolve with age) is probably a key element underlying the contrasting pattern of associations between grade level and burnout dimensions.

The findings relating to teaching context provide novel information. In particular, teaching in an underprivileged area was associated with higher scores for both emotional exhaustion and depersonalization. The number of pupils taught was also associated with higher scores for emotional exhaustion. These contextual factors probably represent special additional challenges in teaching. Their importance for the risk of burnout appears particularly relevant to educational policy, since it is possible to control or change job-related conditions [11].

Burnout has seldom been considered in previous studies to be related to factors outside the work-worker interface, but in our study we found a significant association between marital status and burnout. Indeed, teachers who were single were more susceptible to both depersonalization and reduced personal accomplishment than those living with someone else. Such an association has been reported previously in the general population [47]. This observation supports the hypothesis of the family as a resource factor to cope with stress.

An interesting finding was that motivations for choosing the teaching profession were also related to burnout. Two completely different reasons were considered (job security and feeling a calling for teaching) and these influenced the different dimensions of burnout in opposite directions. Choice of teaching as a profession because of job security was associated with a higher risk of emotional exhaustion and depersonalization, whereas feeling a calling for teaching was linked with a decreased risk of reduced personal accomplishment. It should be noted that in a previous study of teachers carried out by the MGEN Foundation for Public Health [48], feeling a calling for teaching was associated with lower scores to the Ilfeld scale, which measured psychological stress. These results support the hypothesis that idealism in teachers may be a protective factor with respect to certain psychological symptoms. However, a wide gap between ideals and reality has also been shown to be a risk factor of burnout [49].

The present study has certain limitations. Firstly, it is vulnerable to selection bias because of its rather low response rate. As a consequence, representativity could not be ensured. However, the hypothesis that more heavily burdened teachers may be less likely to return their questionnaires is weakened by the fact that the scores on burnout dimensions observed in our final sample were quite similar to those obtained in a representative sample of Italian teachers [29]. It is thus likely that this potential selection bias is limited. As compared to the French population of teachers within the public education system, both younger teachers and university teachers were under-represented in the studied sample, but age and grade level were factored into our models as covariates, so this suboptimal representativity should not influence the association findings. Secondly, the data were cross-sectional and collected from self-report. Reliance on self-reported data for the concomitant measurement of both burnout and its associates does not allow for causal conclusions. In particular, individuals with high negative affectivity may perceive their work context more negatively, which would strengthen artificially the associations between burnout symptoms and work environment. Longitudinal research is needed to identify causal determinants of burnout. A follow-up questionnaire is planned for 2010, and the data collected will be of great interest in this context.

In our study, outcomes of interest were based on the response to the MBI questionnaire. Other tools are available to measure burnout syndrome but not in French language. The French version of MBI has been previously validated in conditions that were rather similar to the present study (postal auto-questionnaire). In the validation study, indices of internal consistency, long-range stability, factorial validity, convergent validity and hypothetico-deductive validity support the general good psychometric properties of the instrument [28]. Cronbach's alphas evaluated in our sample of teachers supported further good internal consistency. Concerning covariates of interest, they were constructed on simple ad hoc questions. Response accuracy and reliability was supposed acceptable, but have not been specifically assessed.

Certain factors that have previously been considered important for burnout were not addressed by the questionnaire used in this study, in particular personality traits and individual resources. Nonetheless, we did consider certain perceptions and attitudes toward the socio-educational environment, namely dissatisfaction with certain aspects of teaching, reasons for choosing the teaching profession and difficulties in various spheres specifically related to the educational setting. We observed that such variables were closely linked with burnout dimensions. However, these associations have to be interpreted cautiously, because reversed causality cannot be excluded.

Our study was restricted to teachers, and the findings thus cannot be generalized to the whole working population, although they clearly have implications for the promotion of health and quality of life in teachers through reducing the risk of burnout. Studies on variables associated with 
burnout among teacher samples are scarce, particularly in France. To our knowledge, only one previous study has investigated cofactors of burnout among French teachers [29]. Our findings are consistent with this study, but given the much larger sample size, we were able to consider a much wider range of covariates, and to conduct adjusted multivariate analyses.

\section{Conclusion}

Our study have highlighted the importance of contextual factors, namely: grade level, socio-professional neighbourhood and number of pupils, as potential determinants of burnout, supporting the possibility of social and organizational solutions in preventing and alleviating this syndrome. Our analyses confirm the multidimensionality of the burnout syndrome, which implies that interventions to reduce burnout should be planned and designed keeping in mind its different components. Longitudinal research is needed to explore the burnout mechanism in teachers further.

\section{Competing interests}

The authors declare that they have no competing interests.

\section{Authors' contributions}

VK and EN designed the study. FG performed the statistical analyses. PB and MNV drafted the manuscript. EN helped to draft manuscript. EN and MNV coordinated the study. MNV critically reviewed the manuscript and carried out all the revisions. All authors read and approved the final version of the manuscript.

\section{Acknowledgements}

This study was supported by the MGEN Foundation for Public Health.

This project was registered with the French data protection authority (CNIL).

\section{References}

I. Maslach C, Jackson SE: The measurement of experienced burnout. J Occup Behav 1981, 2:99-113.

2. Lindblom KM, Linton SJ, Fedeli C, Bryngelsson IL: Burnout in the working population: relations to psychosocial work factors. Int J Behav Med 2006, 13:51-59.

3. Ahola K, Honkonen T, Virtanen M, Aromaa A, Lonnqvist J: Burnout in relation to age in the adult working population. J Occup Health 2008, 50:362-365.

4. Maslach C, Schaufeli WB, Leiter MP: Job burnout. Annu Rev Psychol 200I, 52:397-422.

5. Huberman AM, Vandenberghe R: Introduction - Burnout and the Teaching Profession. In Understanding and preventing teacher burnout Edited by: Vandenberghe R, Huberman AM. Cambridge: Cambridge University Press; 1999: I-II.

6. Byrne BM: The Nomological Network of Teacher Burnout: A Literature Review and Empirically Validated Model. In Understanding and preventing teacher burnout Edited by: Vandenberghe $\mathrm{R}$, Huberman AM. Cambridge: Cambridge University Press; 1999:15-37.

7. Burke RJ, Greenglass ER: Sex differences in psychological burnout in teachers. Psychol Rep 1989, 65:55-63.

8. Unterbrink T, Hack A, Pfeifer R, Buhl-Griesshaber V, Muller U, Wesche H, Frommhold M, Scheuch K, Seibt R, Wirsching M, Bauer J:
Burnout and effort-reward-imbalance in a sample of 949 German teachers. Int Arch Occup Environ Health 2007, 80:433-44I.

9. Russell DW, Altmaier E, Van Velzen D: Job-related stress, social support, and burnout among classroom teachers. J Appl Psychol 1987, 72:269-274.

10. Lackritz JR: Exploring burnout among university faculty: incidence, performance, and demographic issues. Teaching and Teacher Education 2004, 20:713-729.

1I. Kokkinos CM: Job stressors, personality and burnout in primary school teachers. BrJ Educ Psychol 2007, 77:229-243.

12. Friesen D, Sarros JD: Sources of Burnout Among Educators. Journal of Organizational Behavior 1989, 10:179-188.

13. Hastings RP, Bham MS: The Relationship Between Student Behaviour Patterns and Teacher Burnout. School Psychology International 2003, 24: I I5-I27.

14. Naring G, Briet M, Brouwers A: Beyond demand-control: Emotional labour and symptoms of burnout in teachers. Work \& Stress 2006, 20:303-315.

15. Koustelios A: Organizational factors as predictors of teachers' burnout. Psychol Rep 200I, 88:627-634.

16. Cano-García FJ, Padilla-Muñoz EM, Carrasco-Ortiz MÁ: Personality and contextual variables in teacher burnout. Personality and Individual Differences 2005, 38:929-940.

17. Brouwers A, Tomic W: A longitudinal study of teacher burnout and perceived self-efficacy in classroom management. Teaching and Teacher Education 2000, 16:239-253.

18. Friedman IA: Self-efficacy and burnout in teaching: the importance of interpersonal-relations efficacy. Social Psychology of Education 2003, 6:191-215.

19. Evers WJG, Brouwers A, Tomic W: Burnout and self-efficacy: $\mathbf{A}$ study on teachers' beliefs when implementing an innovative educational system in the Netherlands. British Journal of Educational Psychology 2002, 72:227.

20. Brenninkmeijer V, Vanyperen N, Buunk B: I am Not a Better Teacher, But Others are Doing Worse: Burnout and Perceptions of Superiority Among Teachers. Social Psychology of Education 200I, 4:259-274.

21. Chan DW: Hardiness and its role in the stress-burnout relationship among prospective Chinese teachers in Hong Kong. Teaching and Teacher Education 2003, 19:38I-395.

22. Lee RT, Ashforth BE: A meta-analytic examination of the correlates of the three dimensions of job burnout. J Appl Psychol 1996, 81:123-133.

23. Nielsen L, Curtis T, Kristensen TS, Rod Nielsen N: What characterizes persons with high levels of perceived stress in Denmark? A national representative study. Scand J Public Health 2008, 36:369-379.

24. Agyemang C, van Hooijdonk C, Wendel-Vos W, Lindeman E, Stronks $K$, Droomers $M$ : The association of neighbourhood psychosocial stressors and self-rated health in Amsterdam, The Netherlands. J Epidemiol Community Health 2007, 6 1: 1042-1049.

25. Blase J]: A Social-Psychological Grounded Theory of Teacher Stress and Burnout. Educational Administration Quarterly 1982, 18:93-II3.

26. Ministère de la Jeunesse, de l'Education Nationale et de la Recherche: Repères et références statistiques sur les enseignants, la formation et la recherche. Paris 2005.

27. Iwanicki EF, Schwab RL: A cross validation study of the Maslach Burnout Inventory. Educational and Psychological Measurement 1981, 41: II67-II74.

28. Dion G, Tessier R: Evaluation de la traduction de l'inventaire d'épuisement professionnel de Maslach et Jackson. Canadian Journal of Behavioural Science/Revue canadienne des sciences du comportement 1994, 26:210-227.

29. Pedrabissi L, Rolland JP, Santinello M: Stress and burnout among teachers in Italy and France. J Psychol 1993, 127:529-535.

30. Brenninkmeijer V, VanYperen N: How to conduct research on burnout: advantages and disadvantages of a unidimensional approach in burnout research. Occup Environ Med 2003, 60(Suppl I):il6-20.

31. Gold Y: The Factorial Validity of the Maslach Burnout Inventory in a Sample of California Elementary and Junior High School Classroom Teachers. Educational and Psychological Measurement 1984, 44:1009-1016.

32. Byrne BM: Testing for the Factorial Validity, Replication, and Invariance of a Measuring Instrument: A Paradigmatic 
Application Based on the Maslach Burnout Inventory. Multivariate Behavioral Research 1994, 29:289-3II.

33. Maslach C, Jackson SE, Leiter MP: Maslach Burnout Inventory Manual Palo Alto: Consulting Psychologist Press; 1996.

34. Verhoeven C, Kraaij V, Joekes K, Maes S: Job Conditions and Wellness/Health Outcomes in Dutch Secondary School Teachers. Psychology \& Health 2003, 18:473-487.

35. Pomaki G, Anagnostopoulou T: A Test and Extension of the Demand/Control/Social Support Model: Prediction of Wellness/Health Outcomes in Greek Teachers. Psychology \& Health 2003, I8:537-550.

36. Pisanti R, Gagliardi MP, Razzino S, Bertini M: Occupational Stress and Wellness Among Italian Secondary School Teachers. Psychology \& Health 2003, 1 8:523-536.

37. Pascual E, Perez-Jover V, Mirambell E, IvaÃ tez G, Terol MC: Job Conditions, Coping and Wellness/Health Outcomes in Spanish Secondary School Teachers. Psychology \& Health 2003, 18:5II-52I.

38. Sann U: Job Conditions and Wellness of German Secondary School Teachers. Psychology \& Health 2003, 18:489-500.

39. Rasku A, Kinnunen U: Job Conditions and Wellness among Finnish Upper Secondary School Teachers. Psychology \& Health 2003, I 8:44|-456.

40. Griva K, Joekes K: UK Teachers Under Stress: Can We Predict Wellness on the Basis of Characteristics of the Teaching Job? Psychology \& Health 2003, | 8:457-47|.

4I. Kittel F, Leynen F: A Study of Work Stressors and Wellness/ health Outcomes Among Belgian School Teachers. Psychology \& Health 2003, 18:50I-5I0.

42. Jackson SE, Schwab RL, Schuler RS: Toward an understanding of the burnout phenomenon. J Appl Psychol 1986, 71:630-640.

43. Rudow B: Stress and Burnout in the Teaching Profession: European Studies, Issues, and Research Perspectives. In Understanding and preventing teacher burnout Edited by: Vandenberghe R, Huberman AM. Cambridge: Cambridge University Press; 1999:38-58.

44. Gjerdingen D, McGovern P, Bekker M, Lundberg U, Willemsen T: Women's work roles and their impact on health, well-being, and career: comparisons between the United States, Sweden, and The Netherlands. Women Health 2000, 31:I-20.

45. Schaufeli WB, Greenglass ER: Introduction to special issue on burnout and health. Psychology and Health 200I, 16:50I-5I0.

46. Altemus M: Sex differences in depression and anxiety disorders: Potential biological determinants. Hormones and Behavior 2006, 50:534-538.

47. Ahola K, Honkonen T, Isometsa E, Kalimo R, Nykyri E, Koskinen S, Aromaa A, Lonnqvist J: Burnout in the general population. Results from the Finnish Health 2000 Study. Soc Psychiatry Psychiatr Epidemiol 2006, 41: I I-I7.

48. Kovess-Masféty V, Rios-Seidel C, Sevilla-Dedieu C: Teachers' mental health and teaching levels. Teaching and Teacher Education 2007, 23: I I 77-II 192.

49. Schaufeli WB, Enzmann D: The burnout companion to study and practice: a critical analysis London: Taylor \& Francis; 1998.

\section{Pre-publication history}

The pre-publication history for this paper can be accessed here:

http://www.biomedcentral.com/1471-2458/9/333/pre pub
Publish with Biomed Central and every scientist can read your work free of charge

"BioMed Central will be the most significant development for disseminating the results of biomedical research in our lifetime. "

Sir Paul Nurse, Cancer Research UK

Your research papers will be:

- available free of charge to the entire biomedical community

- peer reviewed and published immediately upon acceptance

- cited in PubMed and archived on PubMed Central

- yours - you keep the copyright

Submit your manuscript here:

http://www.biomedcentral.com/info/publishing_adv.asp
BioMedcentral 